\title{
EDUCAÇÃO, TRABALHO E CONCENTRAÇÃO URBANA NO PARQUE TECNOLÓGICO DE CAMPINAS, ESTADO DE SÃO PAULO*
}

Débora Mazza**

Resumo: O trabalho analisa o Parque Tecnológico de Campinas denominado de Região do Conhecimento. Autores têm destacado a importância das cidades como centros de produção, circulação e consumo de bens e coordenação, controle e prestação de serviços para a economia global. Elas têm se configurado como territórios que permitem observar as dinâmicas econômicas, sociais e políticas. Em sintonia com esta perspectiva, o governo do Estado de São Paulo, desde 2008, tem investido em políticas de indução e expansão de polos com afinidades produtivas. O artigo persegue o tipo de relações que se entretecem entre as políticas de industrialização e urbanização que dinamizam os polos de atração, fixação e expulsão dos coletivos que vivem na região de Campinas e como a variável educacional comparece neste feixe de relações.

Palavras-chave: Educação, Trabalho, Cidades, Mobilidade.

\begin{abstract}
The article analyses the so called Technological Park of Campinas, also called of Knowledge Zone. Several authors have been calling attention to the importance of the cities as nucleus to coordinate and control services offered to the global economy - in other terms, as the central place where takes place the production, circulation and consumption of assets and services to the global economy. As a consequence, cities constitute territories in which one may observe economic, social and political dynamics. As per this point of view, since 2008 the Sao Paulo State Government has been investing in policies to induce and expand productive centers. The research aims to understand the kind of interconnection between the industrialization and urbanization policies, which moves the centers of attraction, settlement, and expulsion of human beings living in Campinas and its surroundings. Also, the article aims to ponder how Education matters are treated by/in these interconnections.
\end{abstract}

Key words: Education, Work, Cities, migration

\footnotetext{
* A pesquisa participou do Acordo CAPES COFECUB Processo no. 688/2010-2014

** Departamento de Ciências Sociais e Educação. Faculdade de Educação, UNICAMP. E-mail: dmazza@unicamp.br.
} 
O trabalho analisa o Parque Tecnológico (PT) de Campinas denominado de Região do Conhecimento (RC). O governo do Estado de São Paulo (SP), desde 2008, tem investido em políticas de indução e expansão de polos produtivos, dentre eles o PT. Segundo decretos estaduais um PT é formado por universidades, laboratórios de pesquisa, empresas de tecnologia, prestadoras de serviços e incubadoras que visam o desenvolvimento sustentável da inovação tecnológica, por meio de projetos, programas e ações que articulem os setores público e privado. Aos municípios cabe o papel de atrair processos de inovação tecnológica e promover o aperfeiçoamento no ambiente produtivo e social resultando em novos processos, produtos ou serviços, bem como em ganho de qualidade visando ampliar a competitividade no mercado, a melhoria das condições de vida da população e a sustentabilidade socioambiental.

Autores têm destacado a importância das cidades como centros de coordenação, controle e prestação de serviços para a economia global. Elas têm se configurado como espacialidades que permitem observar as dinâmicas econômicas, sociais e políticas.

Tendo como motivação compreender a Região do Conhecimento do Polo de Tecnologia de Campinas, nos propomos a refletir sobre como as políticas interferem nos processos produtivos, impulsionando a configuração dos espaços de vida, das sociabilidades, das institucionalidades e dos sentidos conferidos pelos coletivos em situações e circunstâncias específicas de urbanidade, fixação e mobilidade. Interessa-nos o tipo de relações que se entretecem entre as políticas de industrialização, urbanização que dinamizam os polos de atração, fixação e expulsão dos sujeitos sociais que vivem na cidade de Campinas e como a variável educacional comparece neste feixe de relações.
Singer $(1973,1980)$ aponta que a industrialização produz concomitantemente transformações nas técnicas de produção, na diversificação de produtos, na alteração da divisão do trabalho e na aglomeração espacial da população em decorrência da necessidade de utilização de infraestrutura de serviços especializados tais como energia, água, esgoto, transporte, comunicações e que os aglomerados industriais reclamam por uma variedade de novos serviços de saúde, educação, pesquisa cientifica, políticas governamentais de financiamento, alimentação, seguro social, habitação etc. A aglomeração espacial das atividades produtivas acaba por produzir uma aglomeração espacial da população e dos bens e serviços públicos e privados.

Neste sentido tipos definidos de industrialização produzem tipos determinados de arranjos locais e institucionais considerando que o jogo econômico produtivo capitalista reclama o subsidio público governamental para a criação de condições infraestruturais que favoreçam a concentração do capital privado. O progresso técnico e a concentração espacial de atividades de bens e serviços são variáveis que alimentam a concentração do capital e que contam com o fomento e financiamento de políticas públicas. (SINGER, 1973, p. 35).

Estas dinâmicas econômicas impulsionam dinâmicas sociais, tais como as migrações produzindo processos de gentrificação, ou seja, concentração de mercados financeiros, serviços especializados, especulação imobiliária, centros comerciais e residenciais, altos salários e conurbação ${ }^{1}$.

${ }^{1}$ Denominamos gentrificação o fenômeno que afeta uma região pela alteração das dinâmicas da composição local acarretadas por projetos de construção, reabilitação, revitalização, tombamento etc. Estes projetos geralmente acarretam à valorização do espaço urbano, o aumento dos custos dos bens e serviços, a especulação imobiliária, a expulsão da população de baixa renda e a mudança no perfil da população. A gentrificação permite capturar as desigualdades e as injustiças de classe criadas pelo mercado imobiliário e pelas políticas urbanas de ocupação do espaço levando, muitas vezes, ao fenômeno da conurbação. 
Entendemos por migração o deslocamento e o alargamento dos "espaços de vida" dos indivíduos, com possibilidades de circulação simultâneas, circulares, cíclicas e/ou pendulares, com temporalidades diferentes considerando o conjunto de atividades realizadas no espaço. Os espaços de circulação, nesta perspectiva, não são apenas os lugares de origem, de transito ou de destino. Eles são lugares de relação, portanto, espaços de vida. Entendemos também que os percursos de circulação, ou seja, os espaços de vida proporcionam construções identitárias que impactam os percursos pessoais, escolares e profissionais. (COURGEAU, 1980).

Assim sendo, as migrações internas e externas são sempre condicionadas historicamente por componentes de mudanças entre os quais os processos de industrialização são fatores extremamente relevantes. As diferentes modalidades de industrialização e de urbanização vinculam-se a diferentes tipos de fluxos migratórios e desenvolvimentos sociais.

Ravenstein (1980) sugere que os centros econômicos dinâmicos transformam-se em polos de atração para populações próximas e distantes e impulsionam oferta de serviços públicos e privados, financiamentos variados, oportunidades múltiplas e fluxos migratórios.

Lee destaca a importância dos obstáculos intervenientes que medeiam os fatores prevalecentes que envolvem a mobilidade humana e a concentração populacional em determinadas cidades. Aponta que se num primeiro momento podemos sugerir que as flutuações econômicas interferem no volume de mobilidade humana e na atração de determinadas regiões; num segundo momento devemos levantar outros fatores que vinculam percursos peculiares entre os lugares de origem e os lugares de destino. Aponta que a educação das crianças, dos jovens e dos adultos, Entendemos por conurbação a unificação da malha urbana de duas ou mais cidades em consequência do crescimento geográfico. As cidades se expandem, prolongando-se para fora de seu perímetro urbano absorvendo áreas rurais e municípios vizinhos. (SASSEN, 1998; SLADER, 2011) a qualidade dos serviços públicos, a estética do lugar seriam obstáculos intervenientes decisivos nos processos de permanência e fixação de grupos no espaço. (LEE, 1980, p. 103).

A lógica econômica pode ser uma chave explicativa para a compreensão das políticas de fomento e financiamento dos Parques Tecnológicos no Estado de São Paulo, da natureza da circulação de pessoas, práticas, saberes e capitais no Parque Tecnológico de Campinas e dos impactos que estas equações provocam nos bens e serviços existentes, fomentados, financiados e ofertados, dentre eles o educacional.

Adotamos como hipótese que o padrão de bens e serviços desenvolvidos pela cidade, em particular a educação voltada para a ciência e a tecnologia, tem transformado Campinas e região num polo de atração e de circulação de tipos específicos de pessoas, práticas, saberes, produtos e capitais (HILLY, 2009; WENDEN, 2001).

Sassen (1991) trabalha com o conceito de "cidade global" para se referir ao grau de influência qualitativa que uma determinada metrópole exerce sobre outros centros urbanos nacionais e mundiais, considerando a posição que ocupa nos quesitos científicos, tecnológicos, intermodais e, principalmente, econômicos. Neste sentido algumas cidades se configuram mais do que apenas cidades grandes, elas criam novas dinâmicas, novas complexidades e novas simultaneidades de eventos. Esta perspectiva de análise difere das que apontam que os mercados globais produzem dispersão espacial e fragmentação produtiva.

Sassen aponta que desde os anos de 1980 tem havido uma amplificação do papel de algumas cidades na economia mundial e que a mobilidade do capital necessita de uma gestão assistida e controlada resultante da interseção de processos fundamentais, tais como:

[...] um grande crescimento da globalização da atividade econômica 
MAZZA. Educação, trabalho e concentração urbana no parque tecnológico de Campinas

tem elevado em escala a complexidade das transações econômicas e aumentado as funções de alto nível nas sedes multinacionais, e a expansão dos serviços das empresas, especialmente de serviços corporativos avançados. [...] é o crescimento da intensidade dos serviços na organização da economia, o processo mais evidente nas empresas de todos os setores industriais, desde a mineração ate o setor financeiro. (SASSEN, 1998, p.2)

O dinamismo econômico de alguns centros urbanos repercute, de modo desigual e combinado nas complexidades das transações que envolvem atividades produtivas dos setores primários, secundários $\mathrm{e}$ terciários; contratos mais ou menos flexíveis; economias formais e informais; transações legais e ilegais; salários estáveis e instáveis. A conurbação mobiliza demandas crescentes de serviços de todos os tipos: das empresas, das indústrias, dos mercados financeiros e do próprio setor de serviços. De fato as cidades são lugares por excelência de produção e diversificação de serviços que configuram uma nova geografia da centralidade e produzem novas formas de marginalidade e de polarização. (CUNHA, 2011; RIZEK, 2013; SASSEN, 2007; TARRIUS, 2010; KOWARICK, 2003).

Assim sendo, algumas cidades tem se configurado como sedes que funcionam como centros de coordenação, controle e serviços que dinamizam economias locais, regionais, nacionais e globais. Elas requerem e abrigam uma infraestrutura física que condensa articulações estratégicas com hiperconcentração de serviços e processos de trabalho atados ao lugar com combinação de recursos e produtos de natureza variada.

Lastrear a pesquisa nas fronteiras da cidade nos permite:
[...] reconstruir o espaço humano para que não seja apenas veiculo de preservação ou de criação de desigualdades sociais $[\ldots]$ mas de reestruturação da sociedade dando aos objetos geográficos e econômicos uma função de liberação do humano. (SANTOS, 1982, p. 81-82).

Estas análises sugerem que diferentes modalidades de industrialização condicionam diferentes projetos de desenvolvimento, políticas sociais e fluxos de pessoas, práticas, saberes, serviços e capitais de modo seletivo na medida em que os sujeitos e os coletivos humanos apresentam condições distintas de responderem aos obstáculos intervenientes que vinculam os fatores que envolvem os locais de origem e de destino. Assim sendo, o Parque Tecnológico de Campinas pode ser pensado num contexto de urbanização particular que produz novas dinâmicas econômicas e sociais na cidade e que repercute na região, no Estado, no nacional e no internacional.

A confluência de condicionantes tem induzido os setores públicos e privados a:

[...] ações estratégicas que visem criação de Políticas Públicas voltadas para fortalecer a Economia do Conhecimento, o Habitat de Inovação e a Criatividade com foco na Sustentabilidade na Região de Campinas como polo de alta tecnologia e Região do Conhecimento (Folder InovaCampinas, 2012, p. 2).

Interessa-nos pesquisar a relação entre as políticas publicas de desenvolvimento, o padrão de industrialização, o oferecimento de bens e serviços, os fluxos migratórios e a qualidade de vida na Região do Conhecimento de Campinas, dando atenção especial 
à variável educacional.

Parte-se de uma perspectiva que combina o estudo das políticas de fomento e financiamento dos Parques Tecnológicos no Estado de São Paulo, seus impactos no desenvolvimento da RMC no incremento de serviços públicos e privados, nas institucionalidades e nas sociabilidades possibilitadas nos espaços da cidade. O olhar multifacetado permite articular analiticamente as relações entre políticas públicas, padrões de desenvolvimento, práticas sociais e representações construídas e expressas no espaço urbano da cidade. (FELDMAN-BIANCO, 2011; REVEL, 1996).

As POLÍTICAS PÚBLICAS E OS PADRÕES DE DESENVOLVIMENTO

A constituição de 1988 criou condições para a reorganização das regiões metropolitanas delegando aos Estados o poder de legislar sobre a organização territorial. A Constituição do Estado de São Paulo, nos seus Artigos 152 e 153, estabeleceram a possibilidade do território ser pensado em regiões metropolitanas, aglomerações urbanas e microrregiões. A Lei Complementar no. 760 de 01/08/1994 considera Região Metropolitana

O agrupamento de municípios limítrofes, com destacada expressão nacional, a exigir planejamento integrado e ação conjunta com união permanente de esforços para a execução das funções publicas de interesse comum, dos entes públicos nela atuantes, que apresente, cumulativamente, as seguintes características: I- elevada densidade demográfica; II significativa conurbação; III- funções urbanas e regionais com alto grau de diversidade; e IV- especialização e integração econômica.

(Em http://www.observatoriometropolitano.agemcamp.sp.gov.br/index. php?option $=$ com_content\&view $=$ ar$\underline{\text { ticle\&id=4\&Itemid }=5}$. Acesso em 01/08/2013).

Contando com esses aportes legais o Estado de São Paulo passou a ser dividido em 15 mesorregiões ou Regiões Administrativas (RA) subdivididas em microrregiões ou chamadas de Regiões de Governo.

Figura 1- Mapa das regiões de governo do Estado de São Paulo

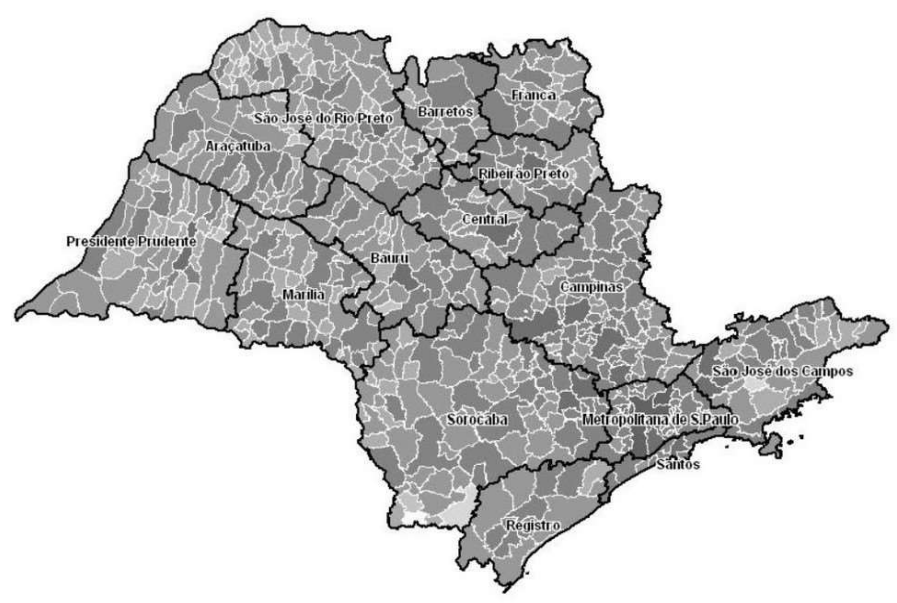

Fonte: Em Portal Cidades Paulistas.

(Em http://www.cidadespaulistas.com.br/prt/cnt/mp-reg-adm. $\underline{\mathrm{htm}}$. Acesso em 18/05/2013).

As mesorregiões são subdivisões utilizadas pelos Estados tendo por finalidade coordenar diversos municípios de uma determinada área geográfica com similaridades econômicas e sociais. Esta divisão foi criada inicialmente pelo Instituto Brasileiro de Geografia e Estatística (IBGE) para fins estatísticos. (Em http://www.ibge.gov.br/home/. Acessado em 18/05/2013)

As 15 mesorregiões administrativas do Estado de São Paulo são agregadas por cidade(s) considerada(s) principal(is) da Região. São elas: Araçatuba, Araraquara, Barretos, Bauru, Campinas, Franca, Marília, Presidente Prudente, Registro, Ribeirão Preto, Santos, São Jose dos Campos, São Jose do Rio Preto, 
São Paulo e Sorocaba

O Estado de São Paulo, segundo o Censo de 2010, atingiu uma população de 41.252.162 habitantes, 95,94\%\% vivendo em áreas urbanas e 58,53\% nas suas áreas metropolitanas institucionais de São Paulo, Santos e Campinas. O grau de urbanização no Estado de São Paulo é bem maior que a da Região Sudeste, de $92,95 \%$ e a do Brasil, de 84,36\%, mostrando uma população rural reduzida, de apenas 1.676 .948 pessoas em 2010. (RIBEIRO, 2012, p. 5)

A urbanização no Estado é crescente. Em 1950 a proporção de população urbana era de $52,59 \%$, subindo para 88,65\% em 1980, 93,41\% em 2000 e atingindo o percentual de $95,94 \%$ em 2010 . O peso da população paulista no total da população brasileira subiu até o ano de 1980, quando São Paulo chegou a possuir quase metade da população do Brasil. Desde então, esta proporção vem descendo lentamente, representando hoje quase $22 \%$ da população brasileira. Até o decênio de 2000-2010 as taxas de crescimento da população paulista eram sempre maiores que as taxas brasileiras. $\mathrm{O}$ incremento absoluto da população paulista na primeira década de 2000 foi de 4.219 .758 pessoas. Grande proporção deste incremento se deu nas 3 regiões metropolitanas institucionais de São Paulo, Campinas e Santos, com aumento de 2.455.441 moradores entre 2000 e 2010, ou seja, mais de $58 \%$ do aumento da população estadual entre 2000 e 2010 aconteceu nessas regiões metropolitanas, indicando a conjugação da urbanização com a concentração populacional. As 3 regiões metropolitanas institucionais eram responsáveis por $58,57 \%$ da população do Estado em 2000, e por 58,53\% em 2010. (RIBEIRO, 2012, p. 6)

A Região Metropolitana de São Paulo tem diminuído lentamente seu peso na população do Estado. Representou quase a metade da sua população em 1980, chegando em 2010 a 47,72\%. As taxas históricas de crescimento populacional do Estado de São Paulo sempre foram superiores as taxas brasileiras, até a década de 2000. Foi apenas na primeira década do século XXI, em 2010, que a taxa de crescimento da população brasileira superou a paulista: a brasileira com valor de $1,18 \%$ ao ano, e a paulista com $1,08 \%$ anuais. Observa-se também o declínio de $40 \%$ no valor da taxa de incremento populacional da Região Metropolitana de São Paulo, que até 1991 costumava ser superior à taxa estadual. Este declínio deve-se, sobretudo, à diminuição do crescimento do município sede.

No Estado mais de $64 \%$ da população reside nas quatro mesorregiões a leste do Estado: Vale do Paraíba Paulista, Macro Metropolitana, Metropolitana de São Paulo e Litoral Sul. As duas mesorregiões ao norte da Mesorregião Metropolitana de São Paulo, Campinas e Piracicaba concentram 12,5\% da população do Estado. Os outros $20 \%$ se distribuem nas outras oito mesorregiões. As mesorregiões a noroeste e a oeste do Estado apresentaram taxas de crescimento populacional baixas, inferiores a $1 \%$ ao ano; as mesorregiões mais centrais: Ribeirão Preto, Araraquara e Bauru, que possuíam, no ano 2010, $11 \%$ da população estadual, já cresceram a mais de $1 \%$; uma das maiores taxas de crescimento se deu na mesorregião de Campinas (1,47\% ao ano). Piracicaba, mesorregião vizinha, também teve taxa expressiva, de 1,23\% anual. As mesorregiões a leste, que circundam a mesorregião Metropolitana de São Paulo, apresentaram altas taxas: Vale do Paraíba Paulista com 1,20\%, Macro Metropolitana com 1,63\%. A mesorregião Metropolitana de São Paulo, integrada pela metrópole institucional de São Paulo mais alguns municípios da Baixada Santista, cresceram a $0,98 \%$ na década. O Litoral Sul, região bastante deprimida, teve crescimento reduzido, de $0,86 \%$ anuais. Há forte associação entre dados econômicos e demográficos. A PAEP de 2001 mostra a existência de forte núcleo na metrópole de São Paulo, complementado com atividade econômica intensa em regiões do seu entorno: Sorocaba, Campinas, São José dos Campos e Baixada Santista - e uma região interiorana com menor escala de produção. É 
também nestas mesorregiões - Vale do Paraíba Paulista, Campinas, Macro Metropolitana - onde se deu o maior incremento demográfico. (RIBEIRO, 2012, p. 7)

A mesorregião administrativa que tem como cidade sede Campinas é considerada pelo Governo do Estado como possuindo logística portuária, ferroviária e rodoviária que facilita o escoamento da produção para o mercado interno e para a exportação. Caracteriza-se ainda pela grande base de pesquisa e desenvolvimento tecnológico contando com instituições de renome internacional; dispondo de abundante mão de obra de alta qualificação tecno-profissional.

Pesquisas apontam que embora $90 \%$ da população se concentrem em áreas urbanas rodeadas por grandes centros industriais como Campinas e Paulínia; existem municípios nos quais prevalecem as atividades econômicas vinculadas à agropecuária, ao setor de serviços e ao turismo. (BEZERRA et alli, 2006).

Campinas a partir da lei complementar estadual 870, de 19 de junho de 2000 se organizou politicamente como cidade sede da Região Metropolitana de Campinas, constituída por vinte municípios paulistas $^{2}$. A região tem se caracterizado por um intenso fluxo de envio e recepção de capitais, mercadorias, pessoas e empreendimentos e também se posicionado como uma das mais dinâmicas no cenário econômico brasileiro destacando-se por sua taxa de crescimento superior à media nacional e representando cerca de 8\% do Produto Interno Bruto (PIB) do Estado de São Paulo.

Campinas tem se consolidado como cidade que dinamiza a RMC pela sua forma de inserção na

2 A Região Metropolitana de Campinas foi constituída por meio da Lei Complementar Estadual 870, de 19 de junho de 2000, e é composta por 19 municípios. São eles: Americana, Arthur Nogueira, Campinas, Cosmópolis, Engenheiro Coelho, Holambra, Hortolândia, Indaiatuba, Itatiba, Jaguariúna, Monte Mor, Morungaba, Nova Odessa, Paulínia, Pedreira, Santa Barbara d'Oeste, Santo Antonio da Posse, Sumaré, Valinhos e Vinhedo. reestruturação produtiva, pela presença de trabalhadores que agregam criatividade e conhecimento e pela construção de certa qualidade de vida no lugar. (MELLO, 2007). É esta microrregião dentro da mesorregião que nossa pesquisa se debruça.

Conforme o Censo de 2010, a Região Metropolitana de Campinas possui 2.832.297 habitantes, distribuídos em $3.647 \mathrm{~km}^{2}$. É a nona maior região metropolitana do Brasil. Nos últimos anos, a região de Campinas tem ocupado uma importante posição econômica nos níveis estadual e nacional. Situada nas proximidades da Região Metropolitana de São Paulo, comporta um parque industrial abrangente, diversificado e composto por segmentos de natureza complementar. Possui uma estrutura agrícola e agroindustrial bastante significativa e desempenha atividades terciárias de expressiva especialização.

Destaca-se ainda pela presença de centros inovadores no campo das pesquisas científico e tecnológico, bem como do Aeroporto de Viracopos - o segundo maior terminal aéreo de cargas do País. Possui ainda uma das maiores refinarias da Petrobras (REPLAN) em produção e sustenta uma produção industrial diversificada - com ênfase em setores dinâmicos e de alto input científico e tecnológico, resultando em crescentes ganhos de competitividade nos mercados interno e externo. (MELLO, 2007).

O potencial produtivo da RMC participa do crescimento e da dinâmica econômica do Brasil que desde 2000 têm produzido fluxos internos e externos de varias espécies. (MARANDOLA Jr, 2011)

O governo do Estado de São Paulo, desde 2008, tem investido em políticas de indução e expansão de Parques Tecnológicos ${ }^{3}$.

${ }^{3}$ No Estado de São Paulo já localizamos o Decreto ${ }^{\circ} 56.424$ de 23/11/2010 que institui e regulamenta a Rede Paulista de Incubadoras de Empresas de Base Tecnológica, de que trata o artigo 24 da Lei Complementar $n^{\circ}$ 1.049, de 2008 (DOE-I 24/11/2010, p. 1); o Decreto $n^{\circ} 54.690$ de $18 / 08 / 2009$ que regulamenta dispositivos que especifica da Lei Complementar $n^{\circ} 1.049$, de 2008 (DOE-I 19/08/2009, p. 1); o Decreto n ${ }^{\circ} 54.196$ de 02/04/2009 que regulamenta o Sistema Paulista de Parques Tecnológicos, de 
Segundo a então coordenadora de Ciência e Tecnologia da Secretaria de Desenvolvimento Econômico, Ciência e Tecnologia do Estado de São Paulo, Desireé Moraes Zouain, em todo o Estado, existem

30 iniciativas para implantação desses empreendimentos. O Parque Tecnológico de São José dos Campos foi o primeiro a receber o status definitivo no sistema, em 2010. Outras dezoito iniciativas estão com credenciamento provisório: Araçatuba, Barretos, Botucatu, mais três em Campinas, Ilha Solteira, Mackenzie-Tamboré, Piracicaba, Ribeirão Preto, Santo André, Santos, duas em São Carlos, São José do Rio Preto, duas em São Paulo e Sorocaba [...] Os parques tecnológicos em negociação são das seguintes localidades: Rio Claro, Americana, Santa Bárbara D'Oeste, Grande ABC, Guarulhos, Jundiaí, Limeira, Pirassununga, Bauru, Atibaia e Campinas.

[...] Um parque tecnológico é formado por: universidades, laboratórios de pesquisa, empresas de alta tecnologia, prestadoras de serviços e incubadoras empresariais e tecnológicas. Neles, são exploradas diversas áreas do conhecimento, dependendo da vocação regional de onde está instalado: mecatrônica, tecnologia da informação, agribusiness, energias limpas, saúde, nanotecnologia, mídia e gerontologia, engenharia de software, biocombustíveis, dentre outras.

( Em: <http://www.saopaulo.sp.gov.

que trata o artigo 24 da Lei Complementar $n^{\circ} 1.049$, de 2008 (DOE-I 03/04/2009, p. 5); o Decreto n ${ }^{\circ} 53.826$ de 16/12/2008 que institui incentivos no âmbito dos parques tecnológicos integrantes do Sistema Paulista de Parques Tecnológicos, de que tratam a Lei Complementar $n^{\circ} 1.049$, de 2008, e o Decreto n. $^{\circ}$ 50.504, de 2006 (DOE-I 17/12/2008, p. 1); o Decreto $\mathrm{n}^{\circ} 53.141$ de 19/06/2008 que institui Grupo de Trabalho para apresentar proposta de regulamentação da Lei complementar n ${ }^{\circ}$ 1049, de 19 de junho de 2008, que dispõe sobre medidas de incentivo à inovação tecnológica, à pesquisa científica e tecnológica, ao desenvolvimento tecnológico, à engenharia não-rotineira e à extensão tecnológica em ambiente produtivo, no Estado de São Paulo, e dá outras providências correlatas (DOE-I 20/06/2008). br/spnoticias/lenoticia.php?i-

$\mathrm{d}=218644 \& \mathrm{c}=5327>$ Acesso em $\underline{08 / 08 / 2012) \text {. }}$

Para Grizendi (2007) o Parque Tecnológico de Campinas

abriga instituições de pesquisa tecnológica tais como o Laboratório Nacional de Luz Síncrotron (LNLS), a Fundação Centro de Pesquisa e Desenvolvimento (CPqD) e cerca de 30 empresas nacionais e multinacionais de base tecnológica, predominantemente da área de tecnologias de informação e comunicação (TIC). Trabalham no Parque aproximadamente três mil pessoas. No entanto, o número de pessoas que circula diariamente atinge cerca de cinco mil, entre trabalhadores e visitantes de negócios. Opera no Parque a incubadora de software do Softex de Campinas, juntamente com o Observatório Digital, núcleo de estudos do Softex Nacional, ambos integrando o Inovasoft, um centro de inovação em software da Unicamp.

[...] O perfil inicialmente definido para o Parque Tecnológico de Campinas e apresentado ao Sistema Paulista de Parques Tecnológicos, foi o de hospedar empresas de base tecnológica de TIC. [...] As TICs aparentemente estão na origem de um novo ciclo global de expansão econômica de longo prazo, constituindo-se em um recente paradigma tecno-econômico. Elas resultam de uma revolução tecnológica, onde o desenvolvimento e a generalização da micro-eletrônica e do software têm sido fundamentais, viabilizando uma nova fase na economia, baseada no conhecimento. As TICs estimulam a contínua automação, afetam setores industriais já existentes e, por si só, criam setores industriais emergentes, provocando assim mudança na estrutura industrial e introduzindo uma 
mudança social mais ampla, com mudanças na estrutura ocupacional e introdução da sociedade da informação. [...] A constatação de que a região metropolitana de Campinas já é um pólo tecnológico de TIC, suportada por um ambiente fértil de C\&T\&I e com instituições como a Unicamp, o Instituto Agronômico de Campinas e Embrapa, somente para citar alguns exemplos, com intensa produção científica e tecnológica, estimula o desenvolvimento do Parque Tecnológico de Campinas.

(Em http://inovacao.scielo.br/scielo. php?script $=$ sci_arttext\&pid $=$ S1808-23942007000200023\&lng= pt\&nrm=is. Acesso em 08/08/2012)

A discussão acerca dos Parques Tecnológicos de Campinas aponta para uma relação direta entre as políticas de fomento e financiamento induzidas pelo Estado de São Paulo, as tendências de desenvolvimento regional, o oferecimento de serviços variados, dentre eles o educacional, o perfil da conurbação e a qualidade de vida prometida na Região do Conhecimento. (CANO \& BRANDAO, 2002).

As POLÍTICAS, AS AÇÕES, AS REPRESENTAÇÕES E OS ESPAÇOS DE VIDA

Passamos agora a relatar algumas ações que, segundo entendemos, mobilizam iniciativas publicas e privadas no sentido de induzir a implementação da vocação para a Ciência e a Tecnologia na RMC.

Primeira ação: Nos dias 11 e 12 de junho de 2012 acompanhamos o Fórum Regional de Inovação e Sustentabilidade \& Mostra de Negócios, Tecnologia, Oportunidades e Empreendedorismo da Região do Conhecimento, realizado no Royal Palm Plaza Resort- Campinas, S.P. O evento contou com a participação direta ou de representantes do Ministro da
Ciência \& Tecnologia, Governador do Estado de São Paulo, Secretário de Desenvolvimento Econômico, Ciência e Tecnologia do Estado de São Paulo, Prefeito de Campinas, Secretario de Desenvolvimento Econômico e Social da Prefeitura Municipal de Campinas, Diretor de Desenvolvimento Econômico de Campinas e Coordenador do Sistema Local de Inovação- Inova Campinas, Conselho de Desenvolvimento da Região Metropolitana de Campinas, da Câmara de Deputados, das Universidades, Empresas e Incubadoras de Tecnologia. Desenvolveu painéis temáticos que, dentre outros, contou com a participação de representantes da Região Metropolitana de Barcelona especialista em Planejamento Urbano, Local e Regional (Ramon Garcia Bragado Acin); do Programa das Nações Unidas para o America Latina e Caribe responsável por políticas e governança de cidades e regiões em habitats inteligentes e do conhecimento (Alain Grimard); do Banco Nacional de Desenvolvimento (BNDES) coordenador de fomento e financiamento voltados às empresas e à inovação (Luciano Coutinho), para citar somente alguns. O evento ocorreu em sequencia à crise de governabilidade do município instaurada por duas comissões processantes que em agosto de 2011 sugeriram o impeachment do então prefeito Helio de Oliveira Santos (PDT- Partido Democrático Trabalhista) acusado de improbidade administrativa em decorrência de irregularidades em limites de gastos, desvios de recursos e precatórios. As comissões processantes levaram a que o então prefeito deixasse o Executivo em dezembro de 2011. A pompa do evento, realizado num dos centros de convenções mais luxuosos do município e região, o escopo das entidades públicas e privadas presentes e a objetividade das propostas construíam uma imagem de que a Inovação e a Sustentabilidade na Região do Conhecimento seguiam mantendo projetos, programas, ações, negócios, oportunidades e empreendedorismo voltados à tecnologia independente das turbulências políticas. O evento objetivou

definir ações estratégicas que visem a criação de Políticas Públicas vol- 
tadas para fortalecer a Economia do Conhecimento, o Habitat de Inovação e Criatividade com foco na Sustentabilidade na Região de Campinas. Fortalecer o posicionamento da Região de Campinas como Polo de Alta Tecnologia e contribuir para estrutura-la como Região do Conhecimento. (Folder InovaCampinas, 2012, p. 2)

Segunda ação: Em 13 de março de 2013 a Prefeitura Municipal de Campinas, sob o comando do novo o prefeito Jonas Donizette (PSB- Partido Socialista Brasileiro), firmou uma parceria com o Centro de Tecnologia da Informação Renato Archer (CTI), unidade de pesquisa do governo federal, com 30 anos de atuação em Campinas, tendo em vista

intensificar a vocação da cidade como polo de conhecimento e produtor de bens e serviços de alto valor agregado. A cidade já é uma referência na área de pesquisa e desenvolvimento, mas precisamos sempre ir além da zona de conforto, identificando novas oportunidades de crescimento.

(Em http://pref-campinas.jusbrasil. com.br/politica/103999969/prefeitura-articula-com-cti-tres-iniciativas-em-ciencia-e-tecnologia). Acessado em 29/04/2013)

A parceria firmada tornou público iniciativas distintas que envolvem os governos municipal, estadual e federal em ações conjuntas na RMC.

São elas:

1- A implantação pelo Ministério da Educação do campus do Instituto Federal de Ensino Superior em Campinas, na região do Campo Grande. A Prefeitura se comprometeu em garantir todas as condições para esta instalação considerando que

os cursos oferecidos se voltarão para a formação de profissionais capazes de atender rapidamente as demandas da indústria.[...] Ao promover o acordo entre o MEC e o MCTI a prefeitura entendeu que o governo federal criou um novo tipo de estrutura para a geração de conhecimento, calcada em experiências internacionais de grande sucesso, como é o caso dos institutos alemães Fraunhofer/Hochschule, e o dos franceses "Carnot". Portanto, esta iniciativa do MEC em conjunto com o MCTI, e contando com o apoio da nova gestão da Prefeitura de Campinas, permitirá um crescimento ainda maior da principal característica da região, que é a capacidade de gerar conhecimento para o setor produtivo. [...] A iniciativa em Campinas adquire uma nova oxigenação pelo lançamento do acordo entre o MEC e o Ministério da Ciência, Tecnologia e Inovação (MCTI), que permitirá o envolvimento de unidades de pesquisa do MCTI nas atividades educacionais do MEC, por meio de institutos federais de ensino, conhecidos como IFES.

(Em http://pref-campinas.jusbrasil. com.br/politica/103999969/prefeitura-articula-com-cti-tres-iniciativas-em-ciencia-e-tecnologia). Acessado em 29/04/2013)

2- O inicio da construção do Parque Científico e Tecnológico do CTI com recursos e área já disponíveis.

A previsão é que a primeira fase do Parque Tecnológico contemple a construção de um prédio de 1,8 mil metros quadrados, com investimentos de R\$ 3 milhões da Financiadora de Estudos e Projetos (Finep), empresa vinculada ao Ministério da Ciência, Tecnologia e Inovação. A primeira fase tem como meta abrigar empresas voltadas para geração de 
MAZZA. Educação, trabalho e concentração urbana no parque tecnológico de Campinas

inovação em bens e serviços de Tecnologia de Informação (TI).

(Em http://pref-campinas.jusbrasil. com.br/politica/103999969/prefeitura-articula-com-cti-tres-iniciativas-em-ciencia-e-tecnologia). Acessado em 29/04/2013)

3- A criação de um Centro de Tecnologia de Energia, Petróleo e Gás em conjunto com a Petrobras compondo o Parque Científico e Tecnológico do CTI

o acordo de parceria com o Centro de Pesquisa e Desenvolvimento (Cenpes) da Petrobras para implantar um Centro de Tecnologia na área de Energia, Petróleo e Gás já foi assinado. $\mathrm{O}$ prédio exigirá investimentos de R\$ 5 milhões e deverá ser construída também no terreno do CTI, já tendo sido contratada a empresa que fará o projeto executivo do edifício.

(Em http://pref-campinas.jusbrasil. com.br/politica/103999969/prefeitura-articula-com-cti-tres-iniciativas-em-ciencia-e-tecnologia). Acessado em 29/04/2013)

4- A lei que institui no município de Campinas, a Semana Municipal de Ciência e Tecnologia, que será realizada em conjunto com a Semana Nacional da Ciência e Tecnologia.

A Semana Nacional de Ciência e Tecnologia é realizada em todo o País em outubro desde 2004, sob a coordenação do Ministério da Ciência, Tecnologia e Inovação (MCTI), através de suas unidades de pesquisa. Em Campinas e região a coordenação é do CTI, que neste ano contará pela primeira vez com o apoio da Prefeitura de Campinas. A finalidade principal da Semana Nacional é mobilizar a população, em especial crianças e jovens, a respeito de temas e atividades de ciência e tecnologia (C\&T). Como acontece a cada ano, as ações são promovidas em torno de uma temática de importância social e conta com a colaboração de entidades e instituições de ensino e pesquisa de todo o território nacional.

(Em http://pref-campinas.jusbrasil. com.br/politica/103999969/prefeitura-articula-com-cti-tres-iniciativas-em-ciencia-e-tecnologia). Acessado em 29/04/2013)

Essas ações tomam como pressuposto que "Campinas já é uma referência na área de pesquisa e desenvolvimento" e que as políticas, os programas, os recursos e as iniciativas devem "fortalecer o posicionamento da Região como Polo de Alta Tecnologia". Apontamos, portanto, a existência de um imbricamento entre políticas, ações, representações que ganham objetividade nos espaços de vida da cidade e região.

\section{Centro e Periferias: o Polo Tecnológico DA Região do Conhecimento}

No contexto da reestruturação global do capitalismo as conexões entre o local, o nacional e o transnacional podem ser apanhadas por meio da visibilidade das cidades e das dinâmicas de atração, fixação e expulsão que elas desenvolvem.

Quanto mais os sujeitos circulam e se desterritorializam tanto mais os poderes políticos públicos são chamados para expandirem sua cobertura. A desterritorialização dos sujeitos não implica no desaparecimento das políticas e dos poderes públicos mas na inclusão de grupos que vivem em contextos marcados por mobilidades. $\mathrm{O}$ estudo da cidade dá visibilidade à conexão entre o local, o regional, o nacional e o trans- 
nacional. (BRAH,1996, SASSEN, 2003, 2007)

Nesta perspectiva a cidade não é meramente uma referência física e uma construção artificial, ela está envolvida em processos vitais das pessoas e dos grupos que a compõem de modo a revelar particularmente a intervenção e a indução humana. Existem forças atuando nos limites urbanos que tendem a ocasionar um agrupamento típico e ordenado da população e das instituições A cidade é ao mesmo tempo uma unidade geográfica, ecológica e econômica e cultural.

Park sugere que a mobilidade dos sujeitos e da população não se mede apenas pela mudança de localidade, mas pelo número e pela variedade de estímulos a que eles são submetidos e que a educação e a capacidade de ler a extensão da economia e os interesses crescentes da vida tendem a despersonalizar as relações sociais e a aumentar a mobilidade dos grupos. Assim sendo, haveria uma conexão entre o dinamismo regional, a mobilidade humana e a capacidade de usar o conhecimento abstrato, daí a importância da educação. $O$ transporte, a comunicação, a segregação da população urbana reclamam a mobilidade dos indivíduos e grupos. Os processos de segregação estabelecem distancias de muitos tipos, inclusive morais, que fazem da cidade um mosaico de pequenos mundos que se tocam e muitas vezes não se interpenetram. Na cidade vivemos e passamos ao mesmo tempo em vários mundos diferentes e contíguos, mas amplamente separados. A cidade mostra em excesso os caminhos da intervenção humana e neste sentido justifica-se a perspectiva de fazer da cidade um laboratório onde a humanidade e os processos sociais podem ser observados. (PARK, 1976)

$\mathrm{O}$ enfoque de escala da cidade e da região nos permite examinar as interseções das hierarquias e das diferentes formas de participação que envolvem os sujeitos e os grupos sociais nestas espacialidades, que são também ambitos de poder. $O$ tamanho da população da cidade e da região, mais do que uma medida absoluta, é um reflexo das relações regionais, nacionais e mundiais que elas mobilizam. Ao tomar esta posição estamos influenciados por uma descrição histórica que articula as políticas publicas, sua implementação nos espaços de vida da cidade, as dinâmicas econômicas e os sentidos de continuo reposicionamento que elas provocam nas populações. (FELDMAN-BIANCO \& GLICK SCHILLER, 2011).

As Regiões Metropolitanas tem permitido observar à relação existente a cidade proclamada, prometida e a cidade vivida.

Como vivem as populações na RMC? Seria possível identificar centralidades e periferias? Como as políticas indutivas intervêm nos processos de redefinição territorial? Como as praticas sociais deslizam e borram as vocações produtivas induzidas pelas políticas? Quais as clivagens que conformam presenças e ausências do Estado e dos equipamentos públicos? Como a "mina de ouro" do controle e do acesso aos cofres públicos reverte para o território e para os diferentes grupos que o ocupam? Como a Região do Conhecimento promove qualidade de vida à população? Como a educação comparece como marcador indutivo de políticas? Como se comporta a mobilidade, a vulnerabilidade e a segregação nos espaços de vida da RMC? Como a dinâmica econômica do município de Campinas se comporta na escala da região?

Cunha (2011) sugere que a produção social do espaço é fruto de relações intrincadas entre o capital privado, o Estado e a sociedade e que as visibilidades destas relações emergem nas formas de ocupação do espaço urbano. As dinâmicas metropolitanas colocam a população interna e externa em movimento e tendem a gerar seletividades especificas em termos demográficos, tais como, sexo, idade, ciclo de vida, nível de escolaridade, perfil profissional, tipo de família, mas também e, sobretudo, em termos socioeconômicos. Esta seletividade vincula-se a segregação sócio espacial e a vulnerabilidade de indivíduos e famílias nas periferias das metrópoles. 
Pesquisas apontam que a mobilidade, a vulnerabilidade e a segregação sócio espacial persistem na RMC apesar de seu dinamismo econômico e de sua vocação de Região do Conhecimento com Inovação e Sustentabilidade. (MARANDOLA JR, 2011).

Cunha (2011) sugere que a mobilidade, a vulnerabilidade e a segregação podem ser observadas a partir das noções de "espaço do bairro" e "geografia de oportunidades".

O "efeito de bairro" pode ser examinado a partir dos marcos normativos existentes no centro e nas periferias por meio da forma como os comportamentos são difundidos, da composição da vizinhança, da proporção de trabalhadores estáveis, da quantidade e da qualidade do capital social, da colaboração vicinal. Existem bairros mais ou menos seguros, protegidos, estigmatizados (CUNHA, 2011, p. 129).

A "geografia de oportunidades" pode ser capturada a partir de elementos objetivos existentes ou não, tais como, acesso a serviços com qualidade de saúde, educação, segurança, lazer; e as características do mercado de trabalho. O lugar onde se vive pode trazer vantagens ou desvantagens na medida em que permite maior ou menor facilidade de acesso a um conjunto de ativos fundamentais para a reprodução da vida e a redução da vulnerabilidade. A localização espacial é expressão objetiva de ativos. Os serviços públicos, privados e a infraestrutura devem ser pensados como ativos considerando a forma como eles são distribuídos e a qualidade de bens e serviços que eles disponibilizam à população. (CUNHA, 2011, p. 130).

Cunha (2009) aponta ainda que embora os serviços públicos sejam relativamente bem distribuídos no espaço, a qualidade do que é oferecido varia sensivelmente de um lugar para o outro e que na Região Metropolitana de Campinas aspectos essenciais ligados à qualidade dos serviços públicos são desfavoráveis nas áreas periféricas. As populações de baixa renda que vivem em áreas mais distantes do centro ou dos polos de atração quase sempre contam com serviços de pior qualidade.

A questão que se coloca é como a RMC, o "vale do silício brasileiro", vai seguir como uma

região sustentável, inovadora e criativa $[\ldots]$ com boas praticas que refletem em investimentos tais como educação, transporte, habitação, resíduos sólidos, saneamento, dinâmica demográfica geridas de modo inteligente e participativo [...] criando um ambiente onde os habitantes possam contribuir para este processo, otimizando seu potencial e focando a transformação da sociedade em catalizadora do desenvolvimento e da sustentabilidade dentro dos limites do planeta. (Folder InovaCampinas, 2012, p. 2)

Como conciliar políticas de desenvolvimento com políticas distributivas em particular na área educacional? Como alargar o acesso e a permanência da população aos bens e serviços educacionais de qualidade socialmente referenciada considerando que a presença de instituições de ensino e pesquisa como a Unicamp, o Instituto Agronômico, a Embrapa etc. apresentaram-se como variáveis determinantes na eleição da RMC como um ambiente fértil para a Ciência e a Tecnologia? Em que medida o PT da RMC aprofunda processos de gentrificação e conurbação entre os habitantes da cidade com marcadores de segregação e estratificação sociais?

São questões importantes que as leis de atração dos fluxos migratórios na região apontam apenas para a ponta do iceberg. 


\section{REFERENCIAS BIBLIOGRÁFICAS}

BEZERRA, Luiza Ma. C. (et alli). Breve perfil dos municípios rurais do Estado de São Paulo. In Pesquisa \& Tecnologia, vol 3, no, 1, jan-jul, (1-7), 2006. Em http://www.aptaregional.sp.gov.br/index.php?option $=$ com_docman\&task $=$ doc_view $\&$ gid $=198 \& I t e-$ $\mathrm{mid}=284$. Acesso em 30/07/2013.

BRAH, Avtar. Cartographies of diáspora. Contestiong identitie. New York: Routledge, 1996.

CANO, W. \& BRANDAO, C. A. (coords) A região metropolitana de Campinas. Urbanização, economia, finanças e meio ambiente. Vol. 1 e 2. Campinas, SP: Editora da Unicamp, 2002

COURGEAU, D. Modelos migratórios simplificados. In MOURA, H. A. de (coord.). Migração interna. Textos selecionados. Fortaleza: BNB (Banco do Nordeste do Brasil)/ETENE (Escritório Técnico de Estudos Econômicos do Nordeste), 1980, p. 267-286.

Methodes de mesure de La mobilite spatiale: migrations internes, mobilite temporaire, navettes. Paris : Editions de l'Institut National d'Etudes Demographiques, 1988.

CUNHA, Jose M. P. (org.) Mobilidade espacial da população. Desafios teóricos e metodológicos para o seu estudo. Campinas: Núcleo de Estudos de PopulaçãoNepo/Unicamp, 2011.

(org.) Sumario de dados de Região Metropolitana de Campinas. Campinas: NEPO/UNICAMP, 2009.

FELDMAN-BIANCO, B. (org.) Nações e diásporas. Estudos comparativos entre Brasil e Portugal. Campinas, SP: Editora da UNICAMP, 2010.

FELDMAN-BIANCO, B. \& GLICK SCHILLER, N. Una conversación sobre transformación de La sociedad, migración, transnacional y trayectorias de vida.
In Critica y Emancipación. Revista Latinoamericana de Ciencias Sociales, Ano III, no. 5, (p. 9-42), Primer Semestre, 2011.

FELDMAN-BIANCO, B. et al. (orgs) La construcción social del sujeto migrante en América Latina. Practicas, representaciones y categorías. Quito: FLACSO, Sede Ecuador: Conselho Latiamericano de Ciencias Sociales, CLACSO: Universidad Alberto Hurtado, 2011.

FOLDER INOVACAMPINAS. Fórum Regional de Inovação e Sustentabilidade \& Mostra de Negócios, Tecnologia, Oportunidades e Empreendedorismo da Região do Conhecimento, 11 e 12 de junho de 2012, Royal Palm Plaza Resort, Campinas, SP, p. 1- 6.

GRIDENZI, E. Alguns aspectos relacionados ao Parque Tecnológico de Campinas. In Inovação Uniemp, versão impressa ISSN 1808-2394, Inovação Uniemp v.3 n.2 Campinas mar./abr. 2007. Em http://inovacao.scielo.br/scielo.php?script=sci_arttext\&pi$\mathrm{d}=\mathrm{S} 1808-23942007000200023 \& \operatorname{lng}=\mathrm{pt} \& \mathrm{nrm}=\mathrm{is}$. Acessado em 08/08/2012.

HILLY, Marie-Antoinette. L'usage de la notion de " circulation migratoire ». In ARAB, C; BABY-COLLIN, V.; BERTONCELLO, B. et al. 2009. Les circulations transnationales. Lire les turbulences migratoires contemporaines. Paris: Armand Colin, pp. 24-28.

KOWARICK, L. Sobre a vulnerabilidade socioeconômica e civil: Estados Unidos, França e Brasil. In Revista Brasileira de Ciências Sociais, Vol. 18, no. 51, (61-85), fevereiro/2003.

LEE, Everett. Uma teoria sobre a migração. In MOURA, Helio A. (coord.) Migração interna: textos selecionados. Fortaleza: Banco do Nordeste do Brasil S.A. BND- ETENE, 1980, p. 89-114.

MARANDOLA JR, E. Mobilidades contemporâneas: distribuição espacial da população, vulnerabilidade e espaços de vida nas aglomerações urbanas. In 
MAZZA. Educação, trabalho e concentração urbana no parque tecnológico de Campinas

CUNHA, Jose M. P. (org.) Mobilidade espacial da população. Desafios teóricos e metodológicos para o seu estudo. Campinas: Núcleo de Estudos de PopulaçãoNepo/Unicamp, 2011, p. 95-116.

MELLO, Leonardo F de. Trabalhadores do conhecimento e qualidade do lugar em Campinas, SP. Tese de Doutorado. Programa de Pós-Graduação em Demografia, IFCH/Unicamp, 2007.

PARK, Robert Ezra. A cidade: sugestões para a investigação do comportamento humano no meio urbano. In VELHO, Otavio Guilherme. O fenômeno urbano. S.P.: Zahar Editores, 1976, p. 26-67.

PREFEITURA MUNICIPAL DE CAMPINAS. Prefeitura articula com o CTI iniciativas em Ciência e Tecnologia, 14/03/2013. (Em http://pref-campinas. jusbrasil.com.br/politica/103999969/prefeitura-articula-com-cti-tres-iniciativas-em-ciencia-e-tecnologia. Acessado em 29/04/2013.)

RAVENSTEIN, E.G. As leis da migração in MOURA, Helio A. (coord.) Migração interna: textos selecionados. Fortaleza: Banco do Nordeste do Brasil S.A. BND- ETENE, 1980, p. 19-88.

REVEL, Jacques. Jogos de Escala. A experiência da microanálise. RJ: Fundação Getulio Vargas, 1996.

RIBEIRO, L. C. de Q. (coord) Os Estados e as Regiões Metropolitanas no Censo 2010. In Observatório das Metrópoles. Instituto Nacional de Ciência e Tecnologia CAPES/FAPERJ/CNPq, 2012. Disponível em: wwww.observatoriodasmestropoles.net . Acessado em 10/12/2015

RIZEK, C. Pensar a periferia é desdobrar alguns aspectos da cidade do presente. In CALHEIROS, A; GONCALVES, A \& MARI, M. (orgs). Marxismo e produção simbólica. Periferia e periferias. SP: Nankin, 2013, p. 9-26.

SANTOS, Milton. Pensando o Espaço do Homem. S.P.: Hucitec, 1982.
SASSEN, Saskia. The Global City. New York, London, Tokyo. Princeton-New Jersey: Princeton University Press, 1991.

Cidades en la economia global: enfoques teoricos y metodologicos. In Revista EURE, Santiago, Vol. 24, no. 71, (p.1-19), mar. 1998.

Localizando ciudades em circuitos globales. In Revista EURE, Santiago, Vol. 29, no. 88, (p.527), diciembre, 2003.

El posicionamento de las ciudades y regions urbanas en una economia global: ampliando las opciones de políticas y gobernaza. In Revista EURE, Santiago, Vol. 33, no. 100, (p.9-34), diciembre, 2007. Los espectros de la globalización. In Revista de Geografia Norte Grande, 39: 95-96 (2008).

SLADER, Tom. Gentrification of the city. In The new blackwell companion of the city. London: by Gary Bridge and Sophie Watson, 2011.

(http://www.geos.ed.ac.uk/homes/tslater/gotcbridgewatson.pdf. Acessado 21/09/2013)

SINGER, Paul. Economia política da urbanização. SP: Ed. Brasiliense, 1973.

Migrações internas: considerações teóricas sobre o seu estudo. In MOURA, Helio A. (coord.) Migração interna: textos selecionados. Fortaleza: Banco do Nordeste do Brasil S.A. BND- ETENE, 1980, p. 211- 244.

Territoires circulatoires et espaces urbains: differenciation dês groupes migrants. In Annales de la Recherche Urbaine, no. 59-60, 1996.

Em: http://1 libertaire.free.fr/Tgv03.html. Acessado em 10/10/2011.

ZOUAIN, Desireé M. São Paulo terá mais Parques Tecnológicos em 2012. Entrevista exclusiva com a coordenadora do Sistema Paulista de Parques Tecnológicos (SPTec). In Portal do Governo do Estado de 
São Paulo. SP: Qui, 19/04/2012 - 15h30. Em http:// www.saopaulo.sp.gov.br/spnoticias/lenoticia.php?i$\mathrm{d}=218644 \& \mathrm{c}=5327$. Acessado em 08/08/2012.

WENDEN, Catherine W. de. Un essai de typologie dês nouvelles mobilités. Hommes \& Migration, Paris : CNRS, no. 1233, 2001, p. 5-12.

TARRIUS, A. Pobres en migración, globalización de las economías y debilitamiento de los modelos integradores: el transnacionalismo migratorio en Europameridional. In Empiria. Revista de Metodología de Ciencias Sociales, Madrid, no. 19, enero-junio, 2010, p. 133-156. 